\title{
Issues in Cluster Development for SMEs in Thailand
}

Amarjeet Singh Mastana

\section{ABSTRACT}

Despite consistent and coherent policy positions from the government concerning small and medium-sized enterprises (SMEs) as a means of stimulating economic development, Thailand continues to suffer from a medium-sized company deficit. One of the means by which it is possible to tackle this issue is through encouragement of cluster formation. This can be successful only when commercial logic already exists and top-down imposition of a cluster where there is no such logic is doomed to failure. In this paper, qualitative research has been used to interview SME business leaders and other relevant stakeholders (with a total sample size of 65) to identify issues related to chuster formation in contemporary Thailand and the means by which they have sought to overcome challenges. These have included low purchasing power, unclear information and uncertainty with respect to the direction of government policy, which has varied wildly over the past two decades, as well as unrealistic loan arrangements. More positively, entrepreneurs detect improvements in the quality and quantity of knowledge workers in the local economy and, when chusters have been able to flourish, reduced transaction costs and better provision of information have helped to create some sustainable forms of competitive advantage. Nevertheless, the perennial complaints of SME owners (i.e. lack of access to capital and markets, government regulations) were also well-represented here. The implications of this rese arch are presented and recommendations made at various scales.

Keywords: clusters, competitiveness, SMEs, Thailand

\section{Introduction}

In common with the situation in most other East Asian countries, the government of Thailand has consistently taken an active role in promoting rapid economic development through the use of industrial policy. The selection of the particular tools of industrial policy (i.e. 'government efforts to alter economic structure to promote productivitybased growth (World Bank, 1993)') have changed over time and the short- and medium-term goals they were intended to reach have also varied and it would be difficult to argue that success has been regularly achieved. Nevertheless, the dedication to government-influenced development has remained. It has been shaped by the persistent nature of several long-term developmental goals: decentralization; escape from the Middle Income Trap and developing new forms of competitive advantage in the contemporary enviromment. These goals have regularly featured in the series of five-year plans, the National Economic and Social Development Plans (NESDPs), created and promulgated by the National Economic and Social Development B oard (NESDB). The need for decentralization was recognised early (Walsh, 2015) and was at first a response to the magnetic influence of Bangkok, the primate city to which so many Thai workers have migrated, leading to pressure on public services in the capital and the formation of slum communities, the social problems resulting from separated families and the democratic deficit resulting from the fact that migrants are only permitted to vote in their home provinces and, hence, live in a place where they have no representation. Consequently, decentralization took on a political aspect, especially when an elected government such as Thai Rak Thai (2001-6) and Pheu Thai (2011-4) relied for its support principally on rural and provincial votes. At the same time, certain provinces and cities have 
started to develop as important economic centres in their own right, in some cases because of their roles as regional centres such as Chiang Mai and Khon Kaen (Glassman \& Sneddon, 2003), in some cases because of cross-border links such as Aranyaprathe (Walsh, 2015) and in other cases because of succes with tourism such as Phuket and Pattaya (Henderson \& Smith, 2009). The spread of the Asian Highway Network (AHN), which will link all major places of consumption and production by road and rail throughout the continent, will intensify the ability of regions to take advantage of emerging economic and commercial opportunities

The Middle Income Trap (Gill \& Kharas, 2007) represents the situation in which a state migh find itself having reached middle income status from low income status through the application of some form of the model of import-substituting. export-oriented, intensive manufacturing with competitiveness based on low labour costs derived from drawing workers from agriculture into industry prior to reaching the Lewisian point and repressio of workers' rights thereafter. Successfully escaping from the Middle Income Trap, which has been achieved in countries such as Korea and Taiwan, also has a significant political element because it requires movement to a society with more rights for the self-expression and creativity necessary for high value added production. Not all recent Thai administrations have been committed to escaping the Middle Income Trap for this reason and, as will be seen later, this is one contributory facto to disappoint growth results in some sectors of the economy.

The third strategic goal has emerged more strongly as the importance of the second became more evident. That is, which economic activities will emerge to replace the low labour cost manufacturing which is no longer viable? A first wave of potential activities was identified by the National Competitiveness Committee (NCC) of Thailand, which was established in 2002 and recommende were processed food, automotive vehicles and parts, fashion, tourism and software, including multimedia and animation. This selection combined existing manufacturing strengths, the application of branding and monetization to activities which have a form of comparative advantage and looking to the example of Korea, in particular. This is a process that helped to strengthen the innovation system in Thailand, albeit from a relatively low base (Intarakumnerd, 2004). This attempt and other which have followed have received mixed results in terms of success. One of the principal lines of attack against the concept of industrial policy has been the tendency it has inspired to make top-down decision about industrial sectors without understanding decisions on the ground and the nature of specific demand and supply conditions. In order to overcome this problem, the most recent attempt to identify particular sectors for development have focused on clusters rather than stand-alone companies. Clusters are regional agglomerations of sector or value chain-related firms and other organizations which chain-related fims and other of sector or value which and collaboration (Porter, 1998:215-6). Currently, the ten industries being promoted in the form of clusters are next-generation cars, smart electronics, affluent, medical and wellness tourism, agriculture and biotechnology, food, robotics for industry, logistics and aviation, biofuels and biochemical, digital and medical services (Arunmas, 2016) Again, this selection depends to some exten on already existing competitive advantages and manufacturing investment together with anticipated future demand. To date, clusters have been used in Thailand to support high-tech manufacturing activities, service sector activities and grassroots community-based activities. These cluster have tended to be successful when appropriatelystructured intermediaries emerge that can mould and improve relationships amongst members and establish suitable modes of action (Interakumnerd, 2005).In some countries, the role of the intermediary could be played at least in part by universities but such linkages with industry are weak in Thailand since there are few incentives for actors to participate in relationships and lack of capacity in fostering relationships (Brimble \& Doner, 2007). Some research indicates that innovation is a low priority in the manufacturing sector in Thailan generally, ranking behind quality, customer-focus and delivery (Phusanat \& Kanchana, 2007)

Large companies generally possess sufficien resources internally to join networks and clusters and nurture the relevant relationships and, indeed, very large firms can effectively form their own clusters. However, there is a need for small- and medium-sized enterprises (SMEs) to participate in clusters and derive benefits from them. This is particularly true in the case of a country such as Thailand where foreign direct investment (FDI) is encouraged as a means of encouraging inward technology transfer, skills development and industrial deepening (Yean \& Hang, 2011). To what extent, therefore, are Thai SMEs able to participate in and benefit from existing and emerging clusters? What barriers inhibit such participants and what resources would be required to overcome them? These are the questions that have informed the current study, which is part of a project featuring qualitative research with in-depth interviews of 65 Thai SME owners and entrepreneus. Theriews were transcribed for subsequent content analysis and the principal results are reported here. Respondents were selected by a combination of convenience and snowball sampling, with some measures taken to combat excessive heterogeneity of sample membership.

The paper continues with a literature review of relevant subjects and then exposition of the principal findings, followed by a discussion of those findings g literature and, then, conclusion incorporating some recommendations.

\section{Literature Review}

\subsection{Clusters and Success}

In his seminal work on clusters and cluster formation, Porter (1998a) wrote that clusters promote better economic growth through improving productivity (i.e. through better access to suppliers and employees, access to specialized information and complementarities), promoting innovation and the formation of new business units. While Porter felt that all members of a cluster benefit from membership, some authors have gone further to argue that cluster presence benefits everyone in geographical proximity (Larreina \& Aguado, 2008), irrespective of membership in the same way that the presence of a trade union benefits nonunion workers (Yates, 2009). Other writers have sought to identify the relevant success factors in comparative studies of clusters across sectors or Cimoni (2005) see success deriving from customer orientation, extended team approach and the use of ICT in new product development. In a study of three agricultural sectors in the low tech context of Lao PDR, Southiseng, and Vilaychur (forthcoming) identified relevant success factors to include interpersonal relationships, market access and the ability to provide acceptable quality of production. Tilson (2001) found that making changes in a supply chain cluster could be successful if entrepreneuria activity by the central actor was achieved and the stakeholders were empowered to participate in such changes. Other studies have placed the emphasis on the contribution of institutions and the presence of organizational learning (e.g. Perez-Aleman, 2005). In less developed countries, it is the presence of local marketplaces and the entrepreneurial ability of practitioners involved which tends to be more important (Sonobe, Hu and Otsuka, 2002). It is evident in the literature that the nature of clusters will vary in response to location-specific, industryspecific and place-specific factors and that they will evolve in the course of time. Few if any studies have focused on the death of clusters or on the backwards steps they might take if evolution leads to lower competitiveness, while nevertheless representing an appropriate response to changes in the environment. However, it is commonly noted that attempting to create a cluster from a top-down approach where one did not exist previously was very likely to be a recipe for failure (Feldman \& Francis, 2004).

\subsection{SMEs}

The definition of SMEs varies from country to country and may incorporate elements of number of employees, amount of capital and turnover, among other indicators. In Thailand, regulations issued by the Ministry of Industry in 2002 define small enterprises as having 50 or fewer employee and up to 50 million baht (manufacturing and service industries with some variations for retail and wholesale sectors) and medium enterprises of up to 200 employees and capital of up to 200 million baht (again with variations in retail an wholesale) (Nagai, 2007). These definitions refer to enterprises that are quite large in scale, when compared to the majority of actual operation which are likely to feature own account worker rather than genuine SMEs. Statistics do not reveal very coherently the actual number of such people. For example, in December 2015, government 
figures show 55.4 million people aged $15+$ in the country, with employment rate of $70.7 \%, 0.25 \%$ unemployed, $0.04 \%$ seasonally unemployed and the remainder $(29.0 \%)$ not in the workforce (NSO, 2016). These figures almost certainly underestimate the unemployment rate, for example.

It is well-established the world over that small businesses suffer from common problems, such as lack of capital, lack of time and skills and lack of market access. Research in Thailand has indicated the positive effect of strategic planning on SME success (Veskaisri, Chan \& Pollard, 2007), the importance of management know-how and various market factors (Chittithaworn et al., 2011), that there are common features of SMEs across the ASEAN region (Tambunan, 2008) and that the government can play an important role in the process through providing an effective national innovation system (Wonglimpiyarat, 2011) as well as other business evelopment services. Neverthe he problem of low levels of technical capacity and value-adding ability within Thai SMEs, which also suffer from the missing middle phenomenon (Harvie, 2010), in which very few if any SMEs are anything bigger than small or even micro-sized in stature.

\subsection{Competitiveness}

The World Economic Forum (WEF) defines competitiveness as "...the set of institutions, policies, and factors that determine the level of productivity of an economy, which in turn sets the level of prosperity that the country can earn (WEF, 2016:4)." The central concept of this is productivity and, in this case, this refers not just to a narrowly defined ration of inputs to outputs with a numerical monetary figure but, instead, any aspect of management and organizational (195rove efficiency and effectiveness (Pritchard, 1995). Porter (1998a) observed that: clusters enhanced productivity and hence competitiveness through providing firms with the opportunity to increase the scale of their operations without having to lose any flexibility. Here, the state can intervene directly and, often, prough encouraging networks of collaborators in terms of innovation and research and development (Nishimura \& Okamuro, 2011) Labour productivity can be an important component factor of overall competitiveness and can arise from cluster formation as a result of proximity of fresters and the ability of workers to move from place to place, not to mention increased competition spurring efficiency gains (Subrahmanya, 2006)

In general, therefore, there are clear connection between SMEs, competitiveness and cluste formation. It would be expected, given the literature, that respondents would talk about their cluster experiences in terms of productivity and efficiencies, from both a positive and a negative perspective. The scaling of organizations should also be found.

3. Findings

The findings are grouped into three broad areas: location; productivity and labour issues and, thirdly, entrepreneurialism and innovation. These areas are now considered individually.

\subsection{Location Issues}

Location issues incorporate two related areas: the physical location of the members of the cluster the nature of the spatial relationships between cluste members. One of the central concepts of the benefit of proximity, which dates back to Marshall (1890), is that regular interactions between partners and cluster members will promote better exchange of information and, potentially, innovation.

Respondents drew distinctions throughout the research between formal and informal contacts and relationships between cluster members. It was observed that information flows are more important and useful when they take place eithe intra-organizationally or via formal relationship inter-organizationally. However, these forma relationships can be affected by casual relationship on either a positive or negative manner. Forma relationships are also likely to guarantee that exact and predictable forms of information will be exchanged and that casual relationships lead to fractured and fragmented discourses.

Formal relationships are not necessarily uniform across the extent of a cluster and neither are they necessarily symmetrical. Information generated an exchanged in one part of a cluster might be withheld

Issues in Cluster Development for SMEs in Thailand

from another part. Some respondents report that there are examples of inter-organizational links taking place such as co-training courses held with both domestic and international organizations.

It was also reported that there are variations in cluster nature and management depending on geographical factors and that the location poses various managerial challenges which are not always being met. Variations could be cultural in nature and there is a need to develop and exploit expertise that is able to flourish in the different locations involved.

Respondents complained about the lack of specific geographical knowledge which might be required to achieve success within particular locations. As is common with research in this area, respondents felt that they were not being provided with sufficient information rather than failing to information through their own resources and that changing signals and policies from different administrations could be confusing and unhelpful.

Proximity of operations provided significant benefits insofar as it contributed to labour pooling which meant that an assortment of skilled workers was available, in a country in which shortages of skilled labour have been pervasive and problematic. Proximity was also felt to contribute to lower transaction costs in terms of transportation, contract negotiations and management and because of the opportunities to generate new business activities based on the resources to hand. Some respondents claimed that they had also detected increasing returns to scale in production, particularly with respect to intermediate goods and that knowledge spillovers were being created which could be used in existing and new forms of production.

However, proximity did also lead to some negative outcomes. For example, especially in some sectors, labour shortages persist and this encourages firms to hold on to them above and beyond what would normally be expected and, consequently, higher competition leads to higher costs.

\subsection{Productivity and Labour Issues}

The ability of firms within a cluster to work together collectively was generally viewed as a positive development. It resulted in cheaper and easier to obtain capital, reduced risk and its attendant expenses, better co-ordination and trust and better access to employees and suppliers and other important stakeholders. Additionally, respondents variously reported improved material efficiency, product efficiency, community relationships an staff commitment. It also reduced the risks of radical innovation through accumulation of knowledge and awareness of design, construction and operation of complex systems and products. Modular production systems can be introduced by which process and production systems are encouraged to develop incrementally. Further, the increase in trust an positive personal relationships led to assurances of higher levels of present and future compliance with regulations in various areas.

There were few if any reports of negative developments in this regard, although there were of course respondents who noted that the positive improvements mentioned above did not occur, even when in some cases it was expected that they would occur.

In general, the benefits which were obtained in this case derived principally from the more efficien organization of existing resources rather than the synergistic generation of new forms of value resulting from co-location. Of course, it is to be expected that the efficiency benefits will be the first to be realised.

\subsection{Entrepreneurialism and Innovation} Issues

Entrepreneurialism and innovation are central to the creation of new forms of business and new types of product but it is not clear exactly how these desirable outcomes can be effectively created. Some conditions are known to be necessary but not sufficient. In the case of this research, respondents observed that innovation is indeed important an represents a means by which new forms and avenues of business will be created. However, it was felt that this was an onerous process and one which is resource-intensive, meaning that $R \& D$ is always expensive and the new software and machinery which qould be required would invoke costs which would have to be passed on to the customers. Respondents observed that knowledge of businessrelated technology is vital to innovation and that the envisioning process is a necessary and importan part of developing innovation as a form of business strategy. However, most respondents still had the 
tendency to think that innovation would be achieved through exogenous rather than endogenous means. would be important, therefore, to encourage mechanisms by which business owners an leaders will more deeply appreciate that busines success must more commonly be developed from within, as Buddhists believe that knowledge and understanding can be developed internally.

When asked about the means of creating new business operations, respondents observed that knowledge is important, as too is access to networks and relationships but, nevertheless, the most important as of business leaders can be increased through the provision of information and through co-operation with foreign partners. Government agencies can enhance the likelihood of new business formation through providing more information and possible international market access. However, it is still the case that respondents feel that they are deprived of opportunities to improve their business activities if they had more access to capital, knowledge about consumer behaviour and market access and access to more skilled and more varied human resources, a lower turnover rate of skilled workers and reduce competition. They also felt that the government imposed upon business operators complex rules and regulations that prevented them from achieving their potential. Government should, they felt, be doing more to reduce regulations and enable business leaders to navigate them successfully. Public sector agencies should also do more to coordinate their opriately and to tackle the issue of corruption.

Nevertheless, respondents felt that they and people like themselves achieved success through their own efforts. They could be successful when they are able to be proactive, be well-resourced, with strong connections and the experience to know how to act in markets, including international markets. When thinking about their colleagues, respondents ended to be less generous, observing that most Thai entrepreneurs lacked skill and knowledge and did not actively seek out necessary information to the extent that was required. They did not manage to adopt new products because they could not tel whether they would be successful and, in other words, were overly risk-averse. Overseas Thai entrepreneurs were thought to have more potential than domestically-based ones in this context.

Overall, the findings indicate that the SME owner and operators are not very strongly bound in to the clusters of which they are a part. The principa benefit that is derived from them is the proximity of factors of production and lower transaction costs as a result

4. Discussion

The fragmented nature of Thai institutions, riddled with many openly anti-democratic individuals and organizations, has meant that democraticallyelected governments have had to seek alternative means of achieving their goals, in the face of resistance (Intarakumnerd, 2011; Chintraruck \& Walsh, 2015). When this has been combined with the need for coalition-building as a means of ensuring the ability to govern, this can lead to contradictions which make the implementation of a coherent platform practically impossible (Lauridsen, 2009). It is not surprising, therefore, that respondent complain about inconsistent government policy in this project (although it might be noted in passing that practitioner respondents tend to complain about the government under any circumstances and wherever they might be found around the world). It is notable that respondents did not converge on a specific set of objectives or policies that they would like to see but, instead, somewhat vague requests for ever more assistance.

It appears from the findings that cluster formation as observed in this project is at a comparatively early stage. This is evident both in the level of development of the economy as a whole, in which personal and personnel management issues are more important than technical complementarities and, also, because the level of interaction between organizations remains limited. Much interaction focuses on competition for scarce resources. It would be expected that longitudinal research, were it conducted, would reveal a maturation of the types and nature of interaction between organizations if the cluster is going to be successful. This factor would explain the lack of comments by respondent relating to the differing scales of operation that have been made possible by the presence of cluster colleagues.

There has been little evidence to date that cluster

Issues in Cluster Development for SMEs in Thailand

formation researched here has led to much in the way of technology transfer or of industrial deepening. This again may be expected to change in the future if success is achieved. The alternative is that there are some factors in the Thai experience reported on here that would challenge existing literature and require change in current understanding. There is not yet sufficient evidence to suspect that this would in fact be the case.

\section{Conclusion}

This paper has attempted to make a contribution to understanding the nature of the formation of clusters within a middle income country with stateled developmental experience and aspirations. It has sought to do this by reporting on a programme of qualitative research featuring in-depth interviews with leading business owners and entrepreneurs in a variety of industries. As ever, such methodology is subject to the limitation of paucity of sample size and, relying in part on a snowball approach, overhomogeneity of the nature of that sample. Time and space limitations further restrict the extent to which this paper can make observations which can be claimed to be generalizable.

The research indicated that cluster formation in this case is at an early stage within the country and within their own trajectories. Consequently, those involved with them value personal management issues above the possibility of adding value to production and taking advantage of differing scales of production. It remains to be seen whether the clusters involved will be able to mature in ways predicted in the literature. There is never any guarantee that businesses at any scale of operation will not fail at some stage.

Respondents and other practitioners are recommended to try to look at the cluster system from a broad perspective so that they might be able to discern the contours of ultimate potential growth that would flow from a mature cluster. One of the most appropriate things for the state to do in this context is to take steps to try to promote that big picture consideration.
6. References

Arunmas, Phusadee, "Government Gives Nod to SEZ Office," Bangkok Post (March 8th 2016), Business B1.

Brimble, Peter and Richard F. Doner, "University-Industry Linkages and Economic Development: The Case of Thailand," World Development, Vol.35, No.6 (2007), pp.1021-36.

Chintraruck, Alin and John Walsh, "Bangkok and the Floods of 2011: Urban Governance and the Struggle for Democratization," in Michelle Ann Miller and Michael Douglass, eds., Disaster Governance in Asia (Springer, 2016), pp.195-209.

Chittithaworn, Chuthamas, Md. Aminul Islam, Thiyad Keawchana and Dayang Hasliza Muhd Yusuf, "Factors Affecting Business Success of Small and Medium Enterprises (SMEs) in Thailand" Asion Social Science, Vol.7, No.5 (2011), pp.180-90.

Ciappei, Cristiano and Christian Simoni, "Drivers of New Product Success in the Italian Sport Shoe Cluster of Montebelluna," Journal of Fashion Marketing and Management: An International Journal, Vol.9, No.1 (2005), pp.20-42.

Feldman, Maryann P. and Johanna L. Francis, "Homegrown Solutions: Fostering Cluster Formation," Economic Development Quarterly, Vol.18, No.2 (2004), pp.127-37.

Gill, I.S. and H.J. Kharas, An East Asian Renaissance: Ideas for Economic Growth (Washington, DC World Bank, 2007)

Glassman, Jim and Chris Sneddon, "Chiang Mai an Khon Kaen as Growth Polies: Regional Industria Development in Thailand and Its Implications for Urban Sustainability," The Annals of the American Academy of Political and Social Science, Vol.590, No.1 (2003), pp.93-115.

Harvie, C., "SMEs and Regional Production Networks," in Vo, T. T., D. Narjoko and S. Oum (eds.), Integrating Small and Medium Enterprises (SMEs) into the More Integrate East Asia. ERIA Research Project Report 2009-8 (Jakarta: ERIA, 2010), pp.19-45. 
Henderson, Joan C. and Russell A. Smith, "The Informal Tourism Economy at Beach Resorts: A Comparison of Cha-Am and Laguna Phuket in Thailand," Tourism land," Tourim Recreation Research, Vol.34, No.1 (2009), pp.13-22.

Intarakumnerd, Patarapong, "Government Mediation and Transformation of Thailand's National Innovation System," Science, Technology and Society, Vol.10, No.1 (2004), pp.87-104.

Intarakumnerd, Patarapong, “Thaksin's Legacy: Thaksinomics and Its Impacts on Thailand's National Innovation System and Industrial Upgrading," Institutions and Economies, Vol.3, No.1 (2011), pp. $31-60$

Intarakumnerd, Patarapong, "The Roles of Intermediaries in Clusters: The Thai Experiences in High Tech and Community-Based Clusters," Asian Journal of Technology Innovation, Vol.13, No.2 (2005), pp.23-43.

Larreina, Mikel and Ricardo Aguado, "Beyond the Cluster: How Wine D Success: 'Oenop tional Journal of Wine Business Research, Vol.20, No.2 (2008), pp.153-70

Lauridsen, Laurids S., "The Policies and Politics of Industrial upgrading in Thailand during the Thaksin Era (2001-6)," Asian Politics and Policy, Vol.1, No.3 (2009), pp.409-34.

Marshall, Alfred, Principles of Economics (London: MacMillan, 1890).

Nagai, Kota, Small and Medium Enterprise Development Policies in Thailand (2007), available at: http:// www.asean.org/storage/images/archive/documents/SME\%20Development $\% 20$ Policies $\% 20$ in $\% 206 \% 20$ ASEAN\%20Member $\% 20$ States $\% 20$ $\% 20$ Part $\% 202$.pdf.

National Statistical Office (NSO), "Summary of the Labour Force Survey in Thailand: December 2015" (2016), available at: http://web.nso.go.th/en/ survey/data survey/050259_summary_December58.pdf.

Nishimura, Junichi and Horoyuki Okamuro, "R\&D Productivity and the Organization of Cluster Policy: an Empirical Evaluation of the Industrial Cluster Project in Japan," The Journal of Technolog Transfer, Vol.36, No.2 (2011), pp.117-44.

Perez-Aleman, Paola, "Cluster Formation, Institutions and Learning: the Emergence of Clusters and Development in Chile," Industrial and Corporate Change, Vol.14, No.4 (2005), pp.651-77.

Phusanat, Kongkiti and Rapee Kanchana, "Competitive Priorities of Manufacturing Firms in Thailand," Industrial Management and Data Systems, Vol.107, No.7 (2007), pp.979-96.

Porter, Michael E., "Clusters and the New Economics of Competition," Harvard Business Review (Nov-Dec, 1998a), available at: http://elibrary. kiu.ac.ug:8080/xmlui/bitstream/handle/1/507/Mikiu.ac.ug:8080/xmlui/bitstream/handle///507/Mithe $\% 20$ new $\% 20$ economics $\% 20$ of $\% 20$ competition.pdf?sequence=1\&isAllowed=y.

Porter, Michael E., On Competition (Cambridge, MA Harvard Business Press, 1998b).

Pritchard, Robert D., "Introduction," in Robert D. Pritchard, ed., Productivity Measurement and Improvement: Organizational Case Studies (Westport, CT: Praeger, 1995), pp.1-7.

Sonobe, T., D. Hu and K. Otsuka, "Process of Cluster Formation in China: A Case Study of a Garmen Town," The Journal of Development Studies, Vol.39, No.1 (2002), pp.118-39.

Southiseng, Nittana, John Walsh and Santisouk Vilaychur, "Cluster Formation for Lao PDR SMEs in Three Sectors," Lao Trade Research Digest (forthcoming).

Subrahmanya, M.H. Bala, "Labour Productivity, Energy Intensity and Economic Performance in Small Enterprises: A Study of Brick Enterprises Cluster in India," Energy Conversion and Management, Vol.47, No.6 (2006), pp.763-77.

Tambunan, Tulus, "Development of SME in ASEAN with Reference to Indonesia and Thailand, $\mathrm{Ch}$ ulalongkorn Journal of Economics, Vol.20, No.1 (2008), pp.53-83, available at: http://www.econ. chula.ac.th/public/publication/journal/2008 cje200102.pdf.
Tilson, Barbara, "Success and Sustainability in Automotive Supply Chain Improvement Programmes: A Case Study of Collaboration in the Mayflower Cluster," International Cluster," International Jounal of Jnovatic Management, Vol.5, No.4 (2001), pp.427-56.

Veskaisri, Kitprem, Peng Chan and Dennis Pollard, "Relationship between Strategic Planning and SME Success: Empirical Evidence from Thailand," Asia and Pacific DSI (2007), available at: http:// iceb.nccu.edu.tw/proceedings/APDSI/2007/papers/Final_14.pdf.

Walsh, John, "Housing in Bangkok: The Spatial and Lifestyle Reconfigurations of a Rapidly Industrializing Society," in Dhruba Kumar Gautam and Yuvaraja Seegodu Eshwarappa, eds., Transforming Management System for Innovation, Development and Governance (Kathmandu: Samjhana Publication Pvt. Ltd., 2015), pp.273-87.

Wonglimpiyarat, Jarunee, "Government Programmes in Financing Innovations: Comparative Innovation System Cases of Malaysia and Thailand," Technology in Society, Vol.33, No.1-2 (2011), pp.15664

World Bank, The East Asian Miracle: Economic Growth and Public Policy (New York, NY: Oxford University Press, 1993).

World Economic Forum (WEF), The Global Competitiveness Report 2015-2016 (Geneva: WEF, 2016), available at: http://www3.weforum.org/docs/ gcr/2015-2016/Global_Competitiveness_Report_2015-2016.pdf.

Yates, Michael D., Why Unions Matter, second edition (New York, NY: Monthly Review Press, 2009).

Yean, Tham Siew and Loke Wei Hang, "Industrial Deepening in Malaysia: Policy Lessons for Developing Countries," Asian Development Review, Vol.28, No.2 (2011), pp.88-109. 